\title{
Management of Rhinophyma
}

\author{
${ }^{1}$ Timothy S Lian, ${ }^{2}$ Richard W Thompson
}

\begin{abstract}
Rhinophyma is a condition that can cause significant disfigurement as well as functional impairment of the nose. It results from hypertrophy and hyperplasia of the sebaceous glands and can be a manifestation of advanced staged rosacea. If left untreated, not only can it cause disfigurement, rhinophyma can also result in nasal airway obstruction by marked ptosis and collapse of the external nasal valve. Surgical excision is the definitive treatment as rhinophyma does not spontaneously regress. Though various surgical techniques are available for the treatment of rhinophyma, a specific technique using tumescent anesthesia, sharp dissection, and argon beam coagulation has been found to be most efficacious. This technique and its advantages are described.
\end{abstract}

Keywords: Epinephrine, Rhinophyma, Surgical excision.

How to cite this article: Lian TS, Thompson RW. Management of Rhinophyma. Int J Head Neck Surg 2016;7(3):188-191.

Source of support: Nil

Conflict of interest: None

\section{INTRODUCTION}

Rhinophyma is a progressive form of acne rosacea and is considered a characteristic of advanced (stage III) rosacea. Phymatous rosacea can occur in the chin, ears, forehead, and eyelids; however, the nose is the most common site of occurrence. Rhinophyma, if left unattended, can result not only in a significant disfiguring appearance of the nose but can also severely compromise the nasal airway due to ptosis of the lower third of the nose. Although a relatively uncommon condition, Dr Fred Stucker ${ }^{1}$ reported on a series of 173 patients with rhinophyma. This series of patients had been managed by most of the reported techniques with mixed results and varying complications. Through the evolution of the treatment of this large series of rhinophyma patients, Stucker concluded that the TWA technique was the most advantageous

${ }^{1}$ Professor and Residency Program Director, ${ }^{2}$ LSUH Shreveport Otolaryngology/HNS Resident

1,2Department of Otolaryngology - Head and Neck Surgery Louisiana State University Health Sciences Center Shreveport Shreveport, Louisiana, USA

Corresponding Author: Timothy S Lian, Professor and Residency Program Director, Department of Otolaryngology Head and Neck Surgery, Louisiana State University Health Sciences Center Shreveport, Shreveport, Louisiana, USA Phone: +3186756262, e-mail: tlian@lsuhsc.edu method of treating rhinophyma. The technique described by Stucker consists of (1) Tumescent anesthesia, (2) Weck blade excision, and (3) Argon beam coagulator (ABC) for hemostasis (TWA). Through his cumulative experience of rhinophyma cases, Stucker reported on the efficacy and expediency of the TWA technique as well as the excellent results and low complication rates. This has led Stucker ${ }^{2}$ to advocate for this technique as the treatment of choice for rhinophyma. The evolution of Dr Stucker's treatment of rhinophyma, the rationale for using the TWA technique, and the technique in detail will all be described.

\section{Evolution of Rhinophyma Treatment}

A number of techniques have been reported in the management of rhinophyma including scalpel excision, ${ }^{3}$ cryosurgery, ${ }^{4}$ electrocautery, ${ }^{5,6}$ and dermabrasion. ${ }^{3,7}$ Prior to 1982 Stucker reported management of rhinophyma with a number of techniques including scalpel excision, cryosurgery, electrocautery, and dermabrasion. Based on the experience of treating the first 40 patients in a series of 173 rhinophyma patients, Stucker concluded that none of these techniques were superior to any other or offered other advantages to employ a particular technique exclusively. Electrocautery offered one of the most expeditious methods; however, this method had the highest complication rate, namely postoperative bleeding and a higher rate of scar formation. ${ }^{1}$

In 1982, Dr Stucker began using the $\mathrm{CO}_{2}$ laser to treat rhinophyma. Carbon Dioxide ${ }_{2}$ laser treatment of rhinophyma possessed clear advantages over other techniques; in particular, the thermal damage was less than that of the electrocautery method while simultaneously offering a modicum of hemostasis. ${ }^{8,9}$ The results were deemed excellent and the complication rates were acceptable. The major disadvantage that Stucker found with the $\mathrm{CO}_{2}$ laser was that this method was relatively time consuming. Treatment for rhinophyma with significant disease is required in excess of 60 minutes of surgical time to achieve the desired result. The vascularity of rhinophyma and the profound oozing from the surgical bed precluded the expeditious vaporization of tissue. Stucker concluded that $\mathrm{CO}_{2}$ laser sculpting to address rhinophyma was a tedious and extremely time-consuming exercise.

Stucker found that the use of tumescent local anesthesia adds significantly to the hemostatic effect. As reported by Dr Stucker, the tumescent anesthesia collapses the small vessels, decreases the bleeding, and enhances 


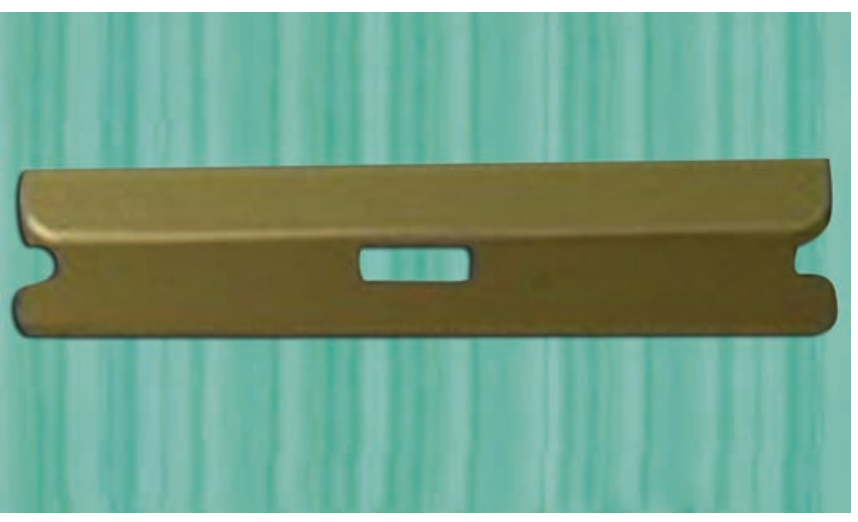

Fig. 1: Weck blade

visualization. Surgeons who anticipate a vasoconstrictive benefit of epinephrine added to the local anesthetic will be disappointed when using it on rhinophyma lesions because epinephrine has no effect on bleeding in rhinophyma as there is no appreciable vasoconstriction effect on these vascular lesions with use of epinephrine. Stucker determined, however, the $\mathrm{CO}_{2}$ laser was not the sculpting instrument to use with the tumescent anesthetic technique as the relatively large volume of local anesthesia needed for tamponading the small vessels required even more time for vaporization with the $\mathrm{CO}_{2}$ laser to sculpt the nose. Stucker subsequently concluded that this time element precluded any advantages of these techniques being used together. Sculpting the disfiguring lesions sharply with a Weck blade and gauging the depths of the resection proved to be straightforward after tumescent anesthesia was employed (Fig. 1). Although this is not a dry wound, sponging allows good scrutiny of the wound and rather precise sculpting of the tissue with a much more accurate assessment of the level of dermis remaining.

Paramount in managing rhinophyma is resecting and sculpting the nasal tip while leaving adequate dermal appendages to preclude scarring and complications. Stucker reported that in managing over 173 rhinophyma patients, his conclusion was that (1) employing tumescent local anesthesia achieves reasonable hemostasis allowing the surgeon to see what is excised and what remains, which is difficult with electrocautery, cryotherapy, and to a lesser extent the $\mathrm{CO}_{2}$ laser; (2) sharp dissection with a Weck blade (Fig. 1) allows for precise excision and sculpting of the nose; (3) absolute hemostasis and a physiologic dressing can be achieved with the ABC (Fig. 2) (ABC, Birtcher Medical Systems, Irvine, CA). ${ }^{10,11}$ Thus, Stucker concluded that the TWA technique in the management of rhinophyma is the most efficacious method of excision and sculpture of the nose which allows for reepithelization and subsequently yields superior results with far fewer problems associated with other techniques. ${ }^{12,13}$

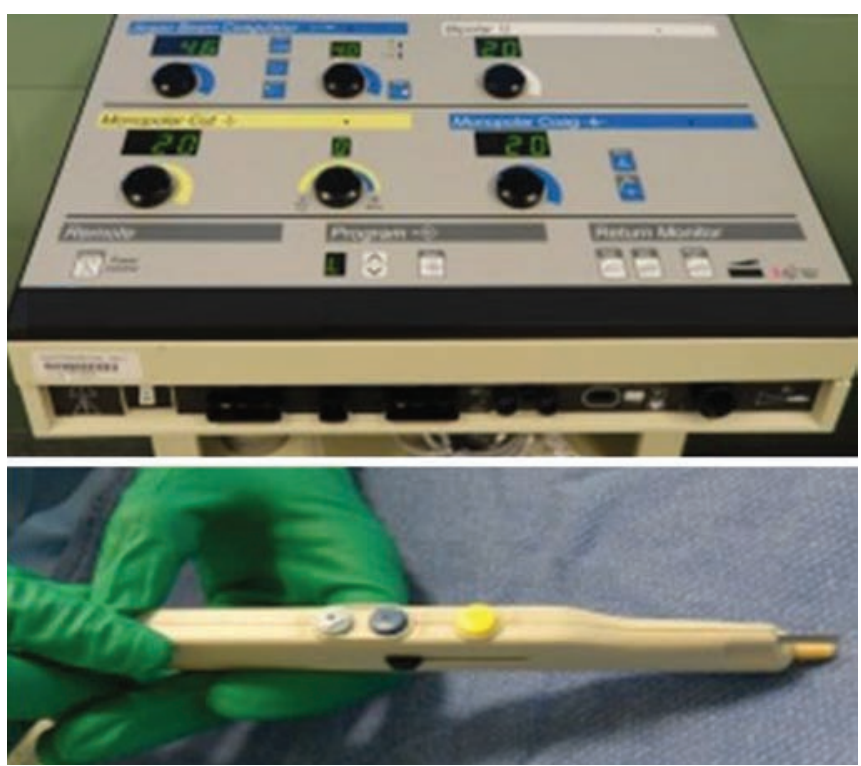

Fig. 2: Argon beam coagulator (Birtcher Medical Systems, Irvine, California)

\section{Technique}

The patient's face is prepared with betadine solution and cleaned with sterile normal saline solution. The face is draped as usual for nasal surgery. The nose is injected with $0.5 \%$ xylocaine with $1: 200,000$ epinephrine, usually 10 to $15 \mathrm{cc}$ of anesthetic solution. General anesthesia is not required. The tumescent infiltration serves the purpose of collapsing vessels within the rhinophyma while also distending the soft tissue rhinophyma tumor from the underlying supporting structure of the nose and enabling more accurate sculpting.

The surgeon inserts the index finger into the nares allowing for a tactile assessment of rhinophyma. This also gives the surgeon an accurate understanding of the level at which the Weck blade will make the initial pass (Fig. 3). It is usual to accomplish the entire sculpting phase in

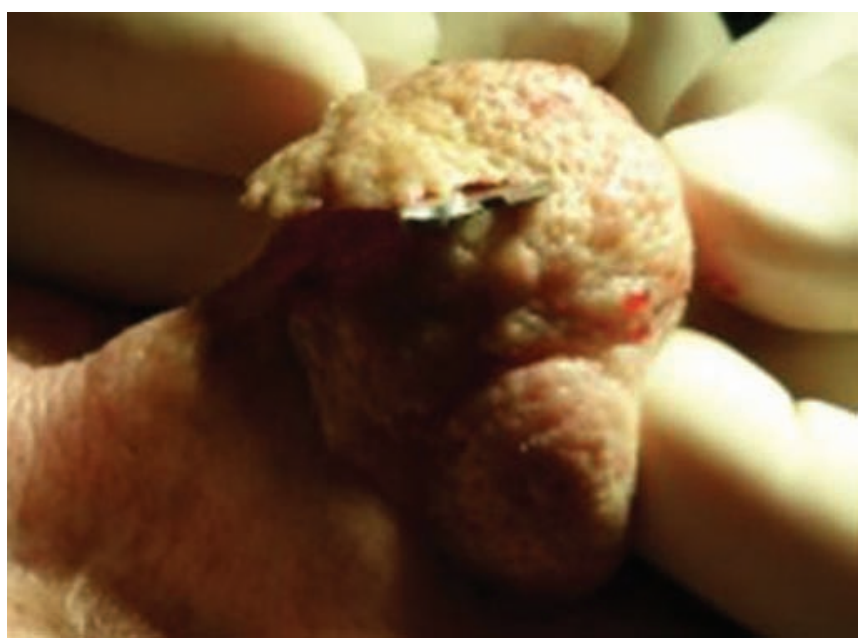

Fig. 3: With the index finger in the nares allowing for a tactile assessment of rhinophyma, the Weck blade is used for excising the initial dorsal stripe of rhinophyma tissue after tumescent anesthesia 


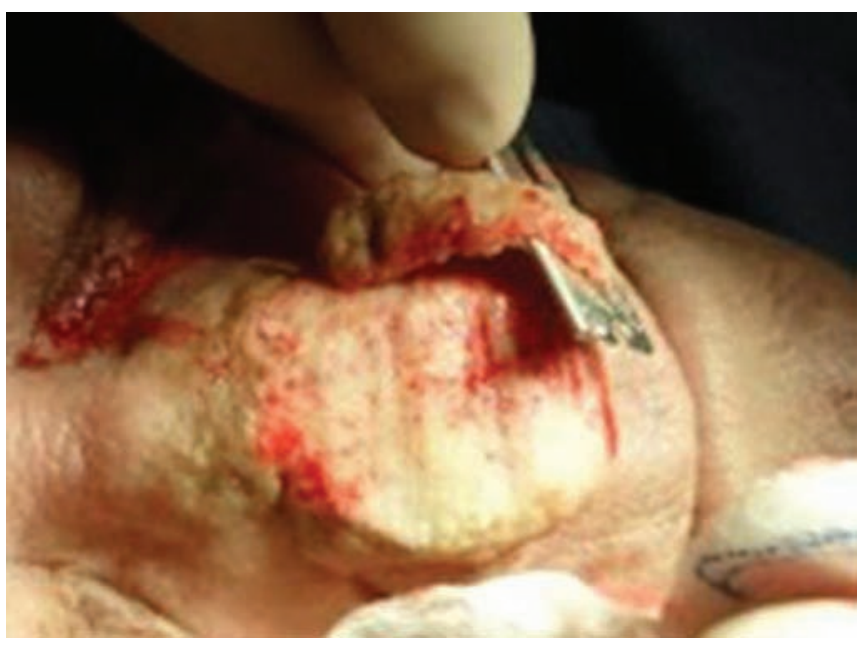

Fig. 4: Sculpting phase using the Weck blade

three to five passes of the Weck blade (Fig. 4). The blade is routinely changed after the completion of two passes secondary to dulling of the blade. Sponging allows appropriate inspection of the tissue at the base of the wound so as to be certain to retain epidermal appendages that are necessary for the regeneration of the epithelial covering without disfiguring scarring. Good visualization also keeps the surgeon from violating the perichondrium of the tip cartilage. Preoperative examination of patients with rhinophyma will often reveal a fissure between a mass of tip and alar rhinophyma tissue. If these fissures are not noted and pointed out to the patient, the fissures may be attributed to the surgeon postoperatively by the patient. One must be very careful to avoid this situation and other potential alar retraction scars.

The rhinophymatous tissue is sculpted and refined to the extent possible. There is a trade-off because complications (scarring) are predictable if not enough dermis and dermal appendages are left behind to allow reepithelialization without obvious or deforming scarring.

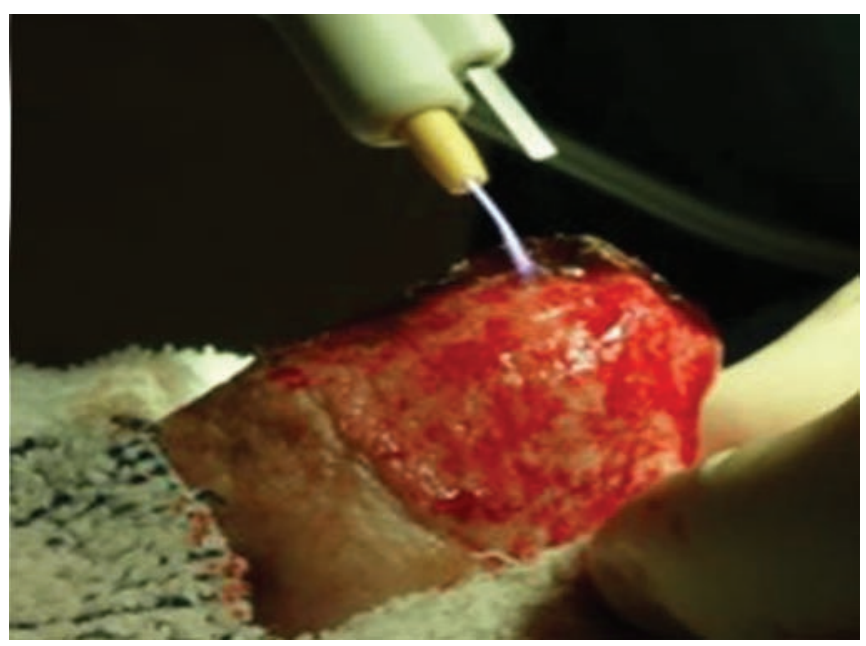

Fig. 5: Hemostasis using the $A B C$

Once resection is complete, the blood in wound bed is blown away with the flow of argon gas to allow a bloodfree surface for hemostasis to be achieved with the ABC (Fig. 5). Vitamin A and D ointment is applied over the physiologic dressing left by the $\mathrm{ABC}$, thus completing the procedure. Typical results using the TWA technique for the treatment of rhinophyma are demonstrated in Figures $6 \mathrm{~A}$ and $\mathrm{B}$.

\section{DISCUSSION}

Rhinophyma is a disfiguring condition that often causes nasal airway obstruction. Medical therapy is rarely helpful, especially in more severe cases, thus rhinophyma is essentially managed by surgery. Many techniques have been developed over the years to address rhinophyma. Stucker's TWA technique in the management of rhinophyma has excellent, reproducible results with minimal time in the operating room. Indeed, Stucker reports an operating time of less than 10 minutes, formation of eschar within 24 hours, reepithelialization within 5 days, and complete
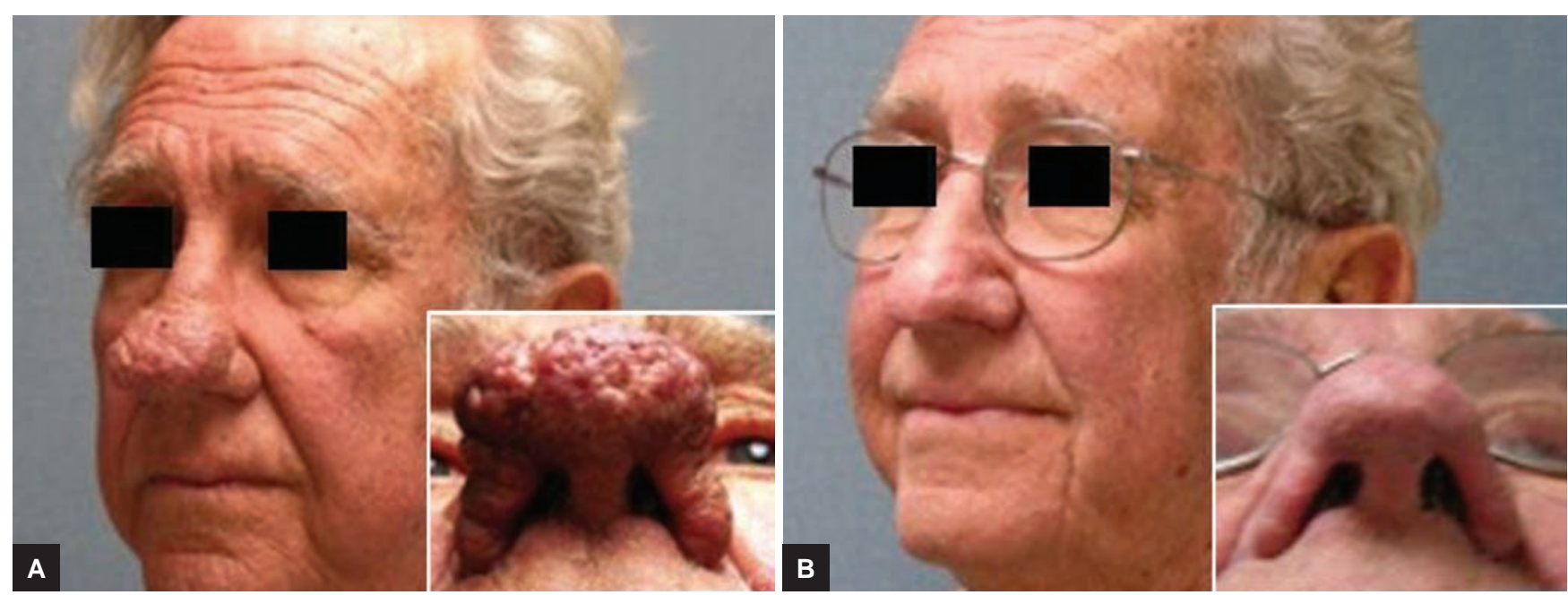

Figs 6A and B: (A) Rhinophyma before treatment; and (B) after final result after treatment of rhinophyma using the TWA technique 
epithelialization occurring typically within 4 weeks. There are a myriad of techniques described for treating this disfiguring problem. Blood loss for this vascular condition has been reported by Stucker as less than 5 cc. All successful techniques must yield a good cosmetic result with acceptable morbidity, low complication rate, and be consistently cost-effective. Techniques employing lasers ${ }^{14}$ or a combination of lasers ${ }^{15}$ or advanced tissue technologies, such as the microdebrider and gelatin-thrombin comixture for hemostasis ${ }^{16}$ are effective, but come at additional cost. Dermabrasion is frequently used as well; however, it is unclear how much the additional time required to perform dermabrasion improves the final result. ${ }^{17}$

\section{CONCLUSION}

Dr Stucker's TWA technique of tumescent anesthesia for tamponade of the vessels, resection using the Weck blade, and coagulation with the $A B C$ is both efficient and effective in addressing rhinophyma. The results are comparable to more expensive and time-consuming techniques. Thus, the TWA technique is the recommended treatment in the management of rhinophyma.

\section{REFERENCES}

1. Stucker FJ, Lian T, Sanders K. The AbCs of rhinophyma management. Am J Rhinol 2003 Jan-Feb;17(1):45-49.

2. Little SC, Stucker FJ, Compton A, Park SS. Nuances in the management of rhinophyma. Facial Plast Surg 2012 Apr;28(2): 231-237.

3. Fisher WJ. Rhinophyma: its surgical treatment. Plast Reconstr Surg 1970 May;45(5):466-470.
4. Sonex TS, Dawber RPR. Rhinophyma treatment by liquid nitrogen spray cryosurgery. Clin Exp Dermatol 1986 May;11(3):284-288.

5. Clark DP, Hanke CW. Electrosurgical treatment of rhinophyma. J Am Acad Dermatol 1990 May;22(5 Pt 1):831-837.

6. Roenick RK. $\mathrm{CO}_{2}$ laser vaporization for treatment of rhinophyma. Mayo Clin Proc 1987 Aug;62(8):676-680.

7. Freeman BS. Reconstructive rhinoplasty for rhinophyma. Plast Reconstr Surg 1970 Sep;46(3):265-270.

8. Shapshay SM, Strong MS, Anastasi GW, Vaughan CW. Removal of rhinophyma with the $\mathrm{CO}_{2}$ laser. Arch Otolaryngol Head Neck Surg 1980 May;106(5):257-259.

9. Wheeland RG, Bailin PL, Ratz JL. Combined $\mathrm{CO}_{2}$ laser excision and vaporization in the treatment of rhinophyma. J Dermatol Surg Oncol 1987 Feb;13(2):172-177.

10. Ward PH, Castro DJ, Ward S. The argon beam coagulator as an effective means of limiting blood loss. Arch Otolaryngol Head Neck Surg 1989 Aug;115(8):921-923.

11. Teimorian B, Duda G, Nickotlem AM, Dumar A. Application of the argon beam coagulator in plastic surgery. Perspect Plast Surg 1991;5:91-98.

12. Stucker FJ, Hoasjoe DK, Aarstad RF. Rhinophyma: a new approach to hemostasis. Ann Otol Rhinol Laryngol 1993 Dec;102(12):925-929.

13. Hoasjoe DK, Stucker FJ, Aarstad RF. Approach to rhinophyma. Facial Plast Surg Clin North Am 1995;3(3):281-285.

14. Fincher EF, Gladstone HB. Use of a dual-mode erbium:YAG laser for the surgical correction of rhinophyma. Arch Facial Plastic Surg 2004;6(4):267-271.

15. Goon PK, Dalal M, Peart FC. The gold standard for decortication of rhinophyma: combined erbium-YAG/ $\mathrm{CO}_{2}$ laser. Aesthetic Plast Surg 2004 Nov-Dec;28(6):456-460.

16. Kaushik V, Tahery J, Malik TH, Jones PH. New surgical adjuncts in the treatment of rhinophyma: the microdebrider and FloSeal. J Laryngol Otol 2003 Jul;117(7):551-552.

17. Curnier A, Choudhary S. Triple approach to rhinophyma. Ann Plastic Surg 2002 Aug;49(2):211-214. 
